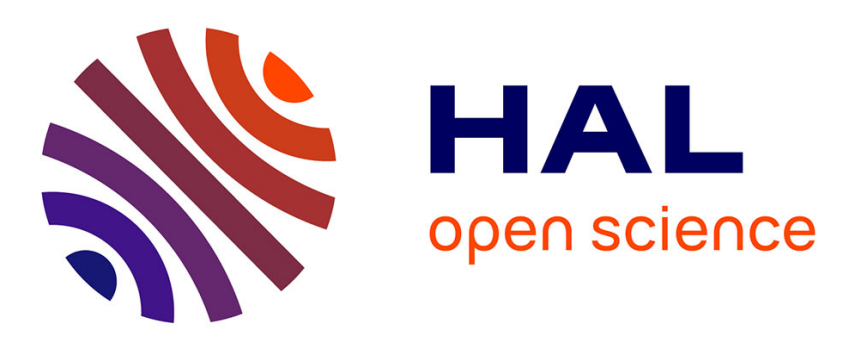

\title{
Preliminary Measurements and Simulations for Space Charges in Aeronautical Cables
}

\author{
E. Aubert, E. Diaw, V. Ury, Séverine Le Roy, G. Teyssedre
}

\section{To cite this version:}

E. Aubert, E. Diaw, V. Ury, Séverine Le Roy, G. Teyssedre. Preliminary Measurements and Simulations for Space Charges in Aeronautical Cables. 2018 IEEE International Conference on High Voltage Engineering and Application (ICHVE), Sep 2018, Athens, Greece. pp.1-5, 10.1109/ICHVE.2018.8642066 . hal-02340303

\section{HAL Id: hal-02340303 https://hal.science/hal-02340303}

Submitted on 21 Nov 2021

HAL is a multi-disciplinary open access archive for the deposit and dissemination of scientific research documents, whether they are published or not. The documents may come from teaching and research institutions in France or abroad, or from public or private research centers.
L'archive ouverte pluridisciplinaire HAL, est destinée au dépôt et à la diffusion de documents scientifiques de niveau recherche, publiés ou non, émanant des établissements d'enseignement et de recherche français ou étrangers, des laboratoires publics ou privés. 


\title{
Preliminary Measurements and Simulations for Space Charges in Aeronautical Cables
}

\author{
E. Aubert* $*^{1}$, E. N. Diaw ${ }^{1,2}$, V. Ury ${ }^{1,2}$, S. Le Roy ${ }^{2}$, G. Teyssedre ${ }^{2}$ \\ R\&T Department, Safran Electrical \& Power, Blagnac, France \\ Université de Toulouse; UPS, INPT; LAPLACE (Laboratory on plasma and conversion of energy) \\ 118 route de Narbonne, F-31062 Toulouse cedex 9, France \\ *e-mail: eddy.aubert@ safrangroup.com
}

\begin{abstract}
This paper deals with the growing need of electrical energy in aeronautical domain, which appears since several years. We focus on HVDC: over the "classical" $28 \mathrm{~V}$ dc, this voltage level is used and will be used more and more for supplying electrical devices. Conduction current measurements were performed on cables for different temperature and electric field values. The objective is to observe a temperature and electric field dependence of the electrical of cables' insulations. The results of current measurements were used as input for multi-physics models. Measurements demonstrate the conductivity varies very slightly with the temperature and field.
\end{abstract}

\section{INTRODUCTION}

The aeronautical domain has faced profound paradigm shifts over the last 20 years, during which the number of electrical and electronic equipment has not ceased to increase, replacing hydraulic and pneumatic loads. Nowadays, there are more than $500 \mathrm{~km}$ of cables in an A380 supplying the electrical loads and insuring the safety of the flight. In order to supply all the equipment and their increasing demand in electrical power, new voltage supplies emerge in the onboard systems: the HVAC (230 V AC variable frequency...instead of $115 \mathrm{~V}$ AC fixed frequency), PWM (Pulse Width Modulation - 10 or 20 $\mathrm{kHz}$ switching frequency) and HVDC (540 V DC in addition to the "classical" $28 \mathrm{~V} \mathrm{DC).}$

The main challenges in aeronautics are the mass and fuel consumption reduction, thus, the mass and the volume of cables have to be extremely reduced. Therefore, the cables' electrical insulation thickness is very small, around $250 \mu \mathrm{m}$. For mechanical, arc tracking, environment and safety reasons, the materials used for aeronautical insulator systems are PI, PTFE, etc.

When combining the voltage levels applied and the thicknesses of the insulation systems, the electrical field constraint becomes extremely important. Under HVDC constraint, space charges might accumulate between the insulator layers and increase locally the electrical fields, accelerating the aging of the cables. In order to predict the space charges associated risks, we need to be able to model the space charges circulations inside and between the insulating layers.

This paper is composed of two chapters. The first one presents a set of experiments and the associated results for the characterization of the insulator materials. The second chapter focuses on the modelling and simulation of cables, using the experimental data described in the previous paragraph. The aim of the simulation part is to obtain the electrical field repartition within the insulator materials. These models will enable the establishment of space charges repartition in the electrical insulation system of aeronautical cables.

\section{EXPERIMENTATION RESULTS}

In order to determine the space charges repartition in the electrical insulators of cables, several steps must be performed, the first one being the identification of the variation on the electrical conductivity of the material versus the electrical field applied. This chapter will describe the test setup and all the preliminary measurements permitting to determine this characteristic of the insulators.

The current study is performed on standard aeronautical cables. We have used an 8 AWG (American Wire Gauge) cable; Table I presents the cable characteristics. One can notice the small thickness of the insulator layers, explaining the high level of electrical field constraint applied on aeronautical cables.

TABLE I

CABLE CHARACTERISTICS USED FOR EXPERIMENTS

\begin{tabular}{|c|c|}
\hline Cable & AWG $\# 8$ \\
\hline Service voltage & $600 \mathrm{~V}$ \\
\hline Conductor & Copper with nickel coated \\
\hline Insulator 1 & Kapton: $50 \mu \mathrm{m}$ \\
\hline Insulator 2 & PTFE special UV: $200 \mu \mathrm{m}$ \\
\hline Service temperature & -55 à $260^{\circ} \mathrm{C}$ \\
\hline $\begin{array}{c}\text { Numbers of streads } \mathrm{x} \\
\text { diameter }(\mathrm{mm})\end{array}$ & $127 \times 0.30$ \\
\hline Conductor Diameter $(\mathrm{mm})$ & Min $: 3,55$ Max $: 3,85$ \\
\hline Cable diameter $(\mathrm{mm})$ & Min $: 4,10$ Max $: 4,40$ \\
\hline Linear masse $(\mathrm{g} / \mathrm{m})$ & Min $: 87,81$ Max $: 90,00$ \\
\hline
\end{tabular}

\section{A. Experimental set up}

An experimental test bench was put in place in order to determine the conductivity vs electrical field characteristics of insulator materials. The aeronautical cable used does not have an external electrode allowing the direct measurement of the electrical conductivity of the insulators.

Figure 1 presents the test setup configuration as follows: a DC high voltage generator is directly connected to the core of the cable. As the cable used does not have an external electrode allowing the direct measurement of the conductivity of the 
insulator, a copper ribbon is placed on the surface of the PTFE layer. The goal is to sandwich the insulators for measurements in the volume. A $4 \mathrm{~cm}$ electrode, placed $1 \mathrm{~cm}$ away from a guard electrode, is connected to an electrometer. A DC voltage is applied on the cable core. The electrometer is interfaced with a computer through a General Purpose Interface Bus (GPIB) for data acquisition. The cable is placed in an oven allowing to vary the temperature from $30^{\circ} \mathrm{C}$ up to $90^{\circ} \mathrm{C}$ with a precision of the order of $1^{\circ} \mathrm{C}$. The measurements were carried out for voltages varying between 0.5 and $10 \mathrm{kV}$ in isothermal condition under different thermal gradients. The duration of polarization / depolarization is 1 hour / 1 hour. Current values are recorded every 2 seconds during the entire polarization / depolarization phase.

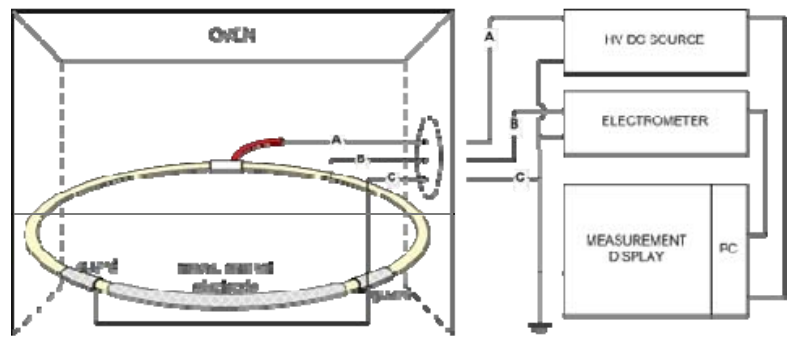

Figure 1. Experimental set up

\section{B. Experimental results}

This subchapter presents the different steps made for determining the variation of the electrical conductivity of insulators as a function of the electrical field and of the temperature, under DC constraint. The insulators were tested at different voltage levels and their response current vs time were observed. [1] Figure 2 shows one of the results obtained for a $13 \mathrm{kV} / \mathrm{mm}$ field level applied.

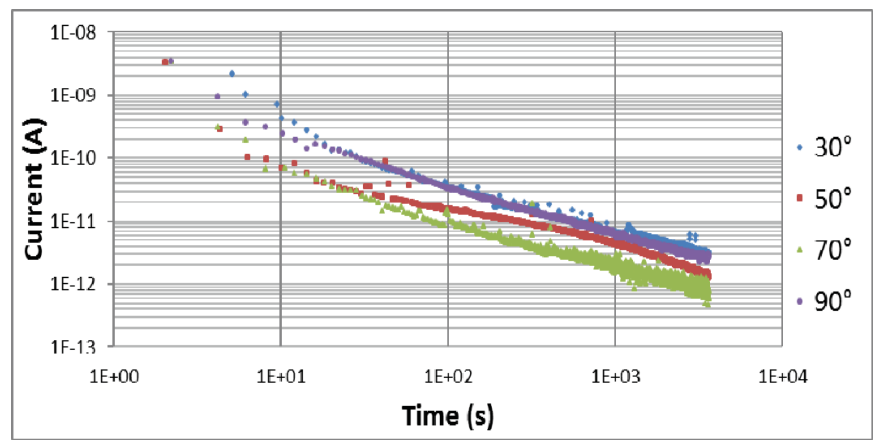

Figure 2. Transient current for different thermal gradients under a polarization of $13 \mathrm{kV} / \mathrm{mm}$

One can observe in Figure 2 the time evolution of the discharge current. Firstly, a rapid decrease of the conduction current which stabilizes around $14-40$ seconds as a function of the applied E field and then appears a nearly constant slope corresponding to a decrease of the current. Whether in polarization or depolarization, we note that the current values are proportional to the applied E fields. It can therefore be supposed that the discharge current comes from the polarization phenomena involved.

At 1 hour, the transient current is still decreasing for all temperatures. It is necessary to intend to increase the time of polarization to observe the stabilization of the current which is going to correspond of conduction current.

Various experimental results from the literature show that in the case of polymer insulators, the conductivity is a function of both the electric field and the temperature. Therefore, we have performed supplementary tests on our cable insulators. Figure 3 shows the evolution of the current density (conduction) versus field strength in the case of PTFE / PI material for four different temperatures. It shows that the slope of the conduction current density characteristics as a function of the field (J-E) is close to a slope of coefficient 1 at a weak field. Any injected charge is immediately extracted in this ohmic regime. As a result, no charges accumulate within an insulating material in isothermal condition [2].

It is possible that under higher fields, the slope becomes greater than 1, thus implying that materials start having anonlinear conductivity.

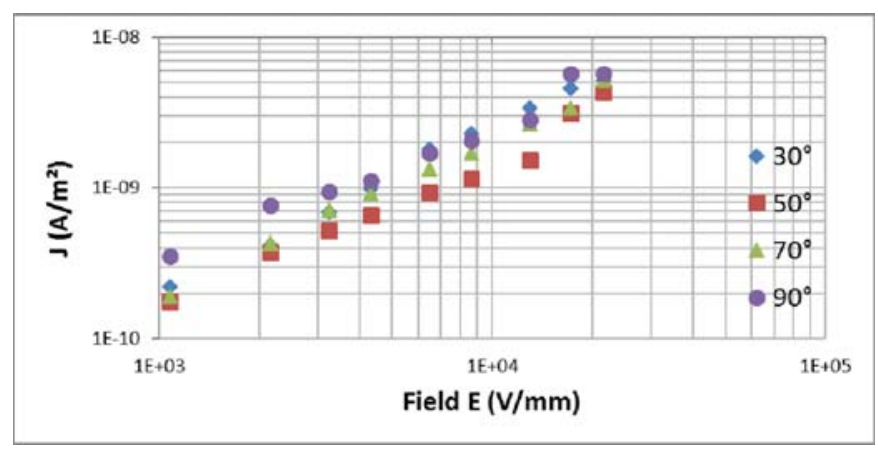

Figure 3. Density of current versus electric field for different temperatures

The objective of this representation was the identification of threshold field values which indicate a change in the current density versus electrical field behavior. As it can be noticed, no threshold can be easily identified in Figure 3. The hypothesis on this non-occurrence of threshold fields is that the applied fields are too weak to have nonlinear behavior that could be attributed to a space charge limited mechanism phenomenon (SCLC) [2].

The final measurements performed were the electrical conductivity versus electrical field under different temperatures $\left(30,50,70,90^{\circ} \mathrm{C}\right)$ and the corresponding results obtained are presented hereby in Figure 4. From the field-current data for 
different temperatures, the dependence of the conductivity as a function of the temperature is shown for some field values $(2$, 13 and $20 \mathrm{kV} / \mathrm{mm}$ ) in Figure 5.

At this stage, given the small electrical conductivity values measured, no immediate conclusions can be drawn concerning the dependence of this parameter on the field or the temperature variations.

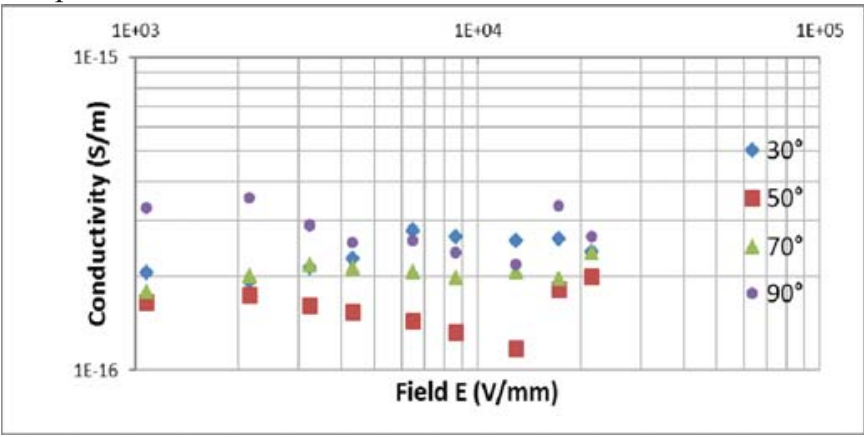

Figure 4. Conductivity versus to the electric field for different temperatures

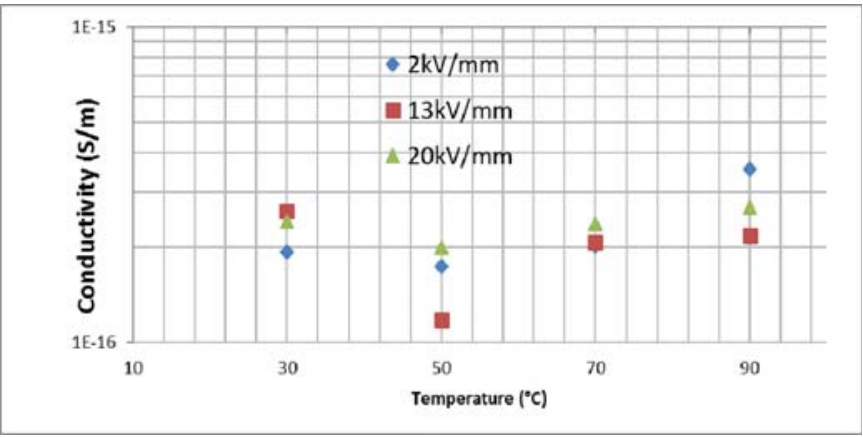

Figure 5. Conductivity versus to temperature for different Electric field

We have noticed that the variation of the conductivity follows an Arrhenius like curve, given by equation (1); it would be possible to characterize the dependence of the conductivity with temperature from an Arrhenius type relationship.

$$
\sigma(T, E)=\sigma 0 * \exp \left(-\frac{E a}{K b T}\right) * \sinh (B(T) \cdot E) \cdot E^{\wedge} \alpha
$$

However, the results show us that the conductivity varies only very slightly with the temperature so the activation energy would be negligible. The same remark would apply to the variation of the conductivity due to the electrical field variation.

As seen previously, the temperature-sensitive conductivity essentially drives the distribution of the electric field in the HVDC-stressed cable. In future experiments, we will increase the maximum temperature and electric field levels to obtain non-linear behaviors. It will permit to integrate (1) in future models.

\section{FEM SIMULATION}

This chapter presents the models and simulations that were performed in order to assess the electric field in the cable. 2D multi-physics (electro-static and thermal) models were developed using a finite element method (FEM) in COMSOL Multiphysics ${ }^{\circledR}$. The cable model consists of two regions: conductor layer and insulation layers (Polyimide and PTFE) as shown in Figure 6.

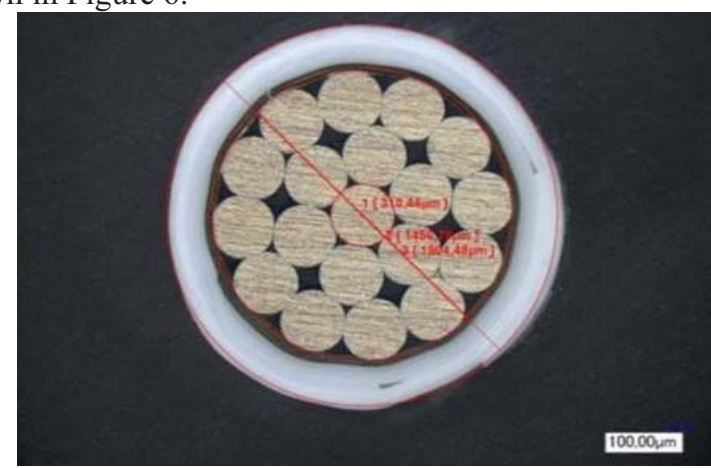

Figure 6. Aeronautic cable observed in the optical microscope

Table II gives the thicknesses of each layer. As shown in Figure 6, 19 wire strands in copper compose the conductor layer and the insulation layers are composed of Polyimide and PTFE sublayers. A gauge 16 AWG cable was chosen in order to reduce the model complexity.

TABLE II. LAYER THICKNESS OF THE CABLE
\begin{tabular}{|l|l|}
\hline Layer & Thickness \\
\hline Conductor & $1.456 \mathrm{~mm}$ \\
\hline Polyimide & $40.73 \mu \mathrm{m}$ \\
\hline PTFE & $184.52 \mu \mathrm{m}$ \\
\hline
\end{tabular}

An "extremely fine" mesh is defined for the different insulator layers (Polyimide, PTFE) and adapted to the thickness of each layer; a "normal" precision mesh is used for the air inside the cable. The mesh of the electrostatic analysis is shown in Figure 7 [3].

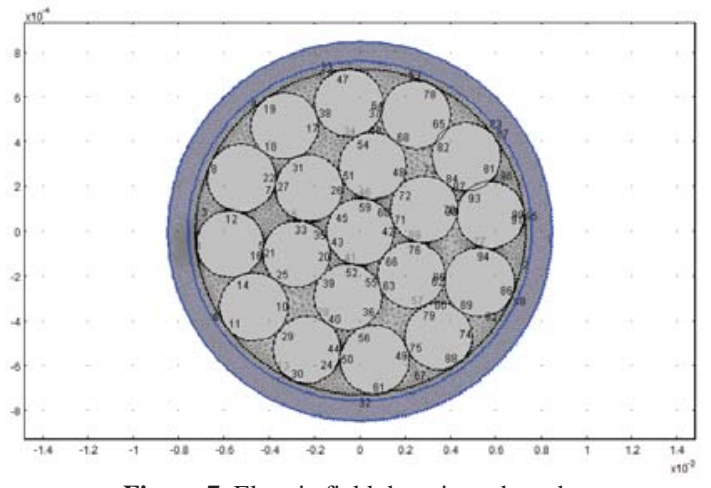

Figure 7. Electric field domain and mesh

Boundaries conditions were defined for the electrostatic analysis. The voltage applied at the wire strands of the cable is 
$540 \mathrm{~V}$. In the real environment of the cable, the electrical reference of the cable can be located within some millimeters from the PTFE layer. To model at best, the electric environment of the cable, we made the hypothesis that there is a layer of air between the PTFE layer and the electrical reference located at $1.88 \mathrm{~mm}$ from the center of the cable.

The electrostatic analysis of this model is based on some assumptions:

- Electrical properties of materials are constant (Table III) except thermal conductivity of copper which depends on the temperature. Electrical conductivity of insulators is supposed to be dependent on the temperature and/or electric field.

- DC voltage is applied to the cable.

In DC cable, the field distribution is resistive and the resistivity of the insulators can depend on nonlinear temperature and electrical field. In this case, electrical conductivity must be characterized for each material in order to supply the numerical model.

In this model, only the dependence on the temperature is considered and electrical conductivity is defined as [4]:

$$
\sigma(T)=A \operatorname{mp}\left(-\frac{D_{n}}{h_{k}}\right)
$$

Where $\mathrm{E}$ is the electric field, $\mathrm{T}$ the temperature, $\mathrm{k}_{\mathrm{B}}$ the Boltzmann's constant and $\mathrm{E}_{\mathrm{a}}$ is the energy of activation.

TABLE III. PROPERTIES OF MATERIALS

\begin{tabular}{|c|c|c|}
\hline Material & Permittivity & Thermal conductivity (W/m.K) \\
\hline PI & 3.4 & 0.15 \\
\hline PTFE & 2 & 0.24 \\
\hline Air & 1 & 24 \\
\hline
\end{tabular}

Equation (3) is the input data used in the numerical model in order to assess the electric field.

The radial distribution of electric field is shown Figure 8. The profile of the electric field below shows a distribution of the electric field, which is different according to the material, used (difference of permittivity).

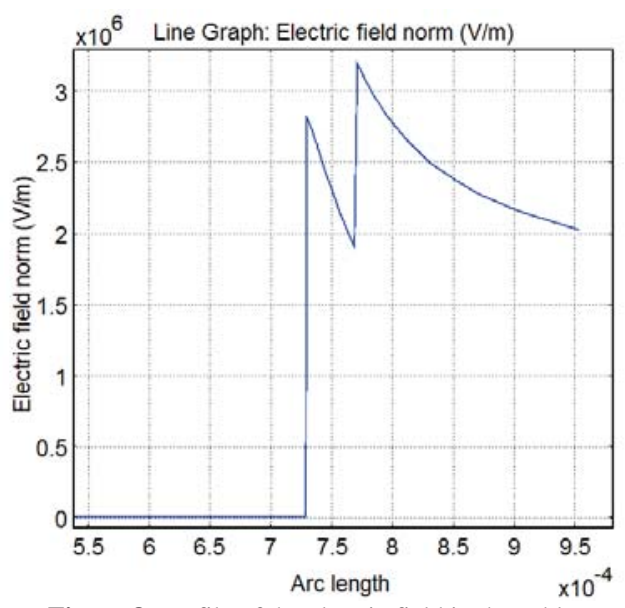

Figure 8. Profile of the electric field in the cable
An intensification of the electric field is observed (Figure 9) near contact points/interfaces between the insulator and the conductive layers.

\section{CONCLUSIONS}

The dielectric tests made it possible to characterize the dielectric behaviors as a function of the electric field and the temperature.

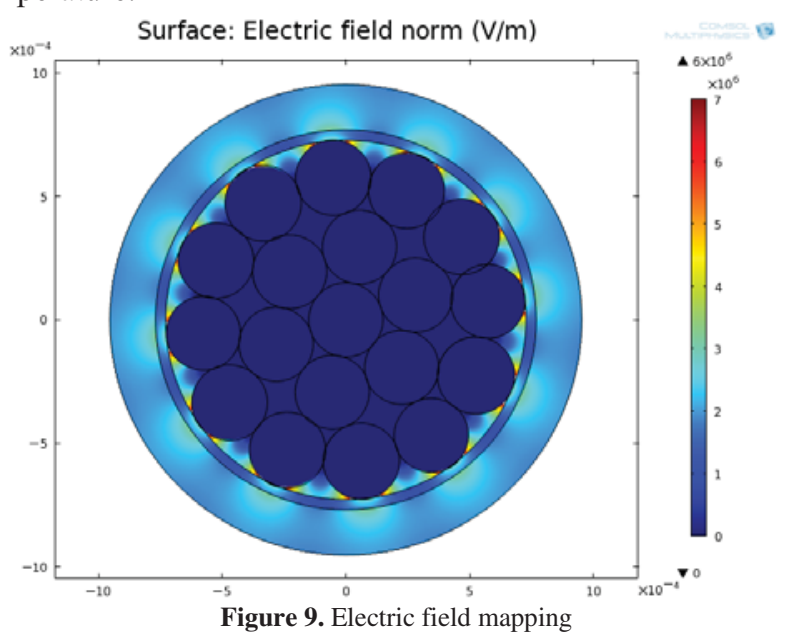

Indeed, these two parameters can be at the origin of the accumulation of charges within the insulator consequently responsible for a local intensification of the field in the dielectric, which can generate a premature aging of the cable. The dielectric characterizations of the samples made it possible to determine the dielectric behavior of the cables used under HVDC constraints. The results made it possible to demonstrate a linearity of the conduction current in the insulator as a function of the electric field. Contrary to our expectations, the temperature in the $\left[30^{\circ} \mathrm{C}-90^{\circ} \mathrm{C}\right]$ range is not an aggravating factor on the generation of the conduction current. Indeed, the results showed that the conductivity and therefore the resistivity did not vary a lot with the temperature and very slightly with the electric field within the defined limits.

The macroscopic model developed in this study allowed the construction of a precise cable model with respect to its real geometry, materials used, but also their electrical characteristics obtained previously by measurement. The 2D coupled electrostatic-thermal simulation and the stationary study allows determining the distribution of the electric field in the insulator layers.

In the future, it will however be necessary to take into account the transport and the electrical charges accumulation in the volume of insulator materials or at the interfaces between different insulators through a microscopic temporal model of transport of charges (to have space charge results simulations). These models will be completed by experimental results space charge of insulator samples.

\section{REFERENCES}


[1] Y. SEGUI, « Diélectriques -Courants de conductions,» Techniques de l'ingénieur, vol. d2301, p. 4, 2000.

[2] Fabiani et al., «Polymeric HVDC Cable Design and Space Charge Accumulation» IEEE Electr. Insul. Mag, vol. 23, n 16, pp. 11-19, 2007.

[3] Thi Thu Nga Vu, Gilbert Teyssedre, Séverine Le Roy, Christian Laurent, "Effet Maxwell-Wagner dans des multicouches: mesure et modèle de la charge d'interface", Symposium De Genie Electrique, SGE 2016, Grenoble, France.

[4] S.Le Roy, G. Teyssedre and C. Laurent, "Modelling Space Charge in a Cable Geometry", IEEE Trans. Dielectr. Electr. Insul. Vol. 23, No.4; August 2016 